\title{
APLIKASI SERBUK ARANG TONGKOL JAGUNG DAN SERBUK CANGKANG KERANG MUTIARA SEBAGAI MEDIA CARBURIZER PROSES PACK CARBURIZING BAJA KARBON RENDAH
}

\author{
Sujita \\ Universitas Mataram dan Jalan Majapahit No 62 Mataram \\ 0370 - 636126 \\ E-mail: sujita@unram.ac.id
}

\begin{abstract}
Carburizing process on low carbon stell can be done by using carburizer of corncob charcoal, pearl oyster shell powder. Cylindrical low carbon steel of AISI 1018 was used in the present study. The materials put inside the pack carburization with carburizer and pearl oyster shell powder. The pearl oyster shell powder varies of 5, 10, 20, and 25 weight percentage. The temperature of $910^{\circ} \mathrm{C}, 930^{\circ} \mathrm{C}$, and $950^{\circ} \mathrm{C}$ was used to heat the materials with holding time of 90 and 150 minutes. Then, hardness Vickers test and microstructure test using scanning electron microscope (SEM) was used to analyze the hardness number of each materials. The results shown that the hardness number increased up to $262,47 \mathrm{~kg} / \mathrm{mm}^{2}$ (82 \%) from $144,08 \mathrm{~kg} / \mathrm{mm}^{2}$ by adding $20 \%$ weight of pearl oyster shell powder with heating and holding time of $950^{\circ} \mathrm{C}$ and 150 minutes, respectively. From microstructure and composition test reveal that surface hardening occurred on the low carbon steel surface due to carbon diffusion during pack carburizing process.
\end{abstract}

Keywords: Corncob charcoal, pearl oyster shell powder, pack carburizing, low carbon steel

\section{PENDAHULUAN}

Hasil alam Indonesia sangat melimpah, termasuk beberapa jenis hewan yang terdapat di dalamnya. Salah satunya adalah Kerang mutiara (Pearl) yang merupakan salah satu hewan jenis moluska. Hewan jenis ini paling sering dijumpai di daerah persawahan dan merupakan musuh petani karena dapat merusak tanaman padi. Untuk melindungi tanamannya, para petani berusaha untuk membasmi kerang mutiarasehingga tanaman petani dapat terhindar dari kerusakan. Ternyata kerang mutiarayang semula hanya merugikan para petani kini dapat dimanfaatkan karena cangkang kerang mutiaramengandung kalsium karbonat $\left(\mathrm{CaCO}_{3}\right)$ yang dapat dijadikan sebagai energizer alternatif di dalam proses karburisasi padat selain barium karbonat $\left(\mathrm{BaCO}_{3}\right)$.

Pada dasarnya bahan-bahan yang digunakan dalam karbonisasi yaitu, arang kayu, arang batok kelapa, dan arang kulit. Untuk mempercepat proses karbonasi maka di tambahkan barium karbonat $\left(\mathrm{CaCO}_{3}\right)$, natrium karbonat $\left(\mathrm{NaCO}_{3}\right)$ atau kalsium karbonat $\left(\mathrm{CaCO}_{3}\right)$. Ketiga bahan tambahan tersebut termasuk jenis bahan-bahan pembangkit tenaga dalam proses karburisasi. Karburisasi dilakukan dengan cara memanaskan bahan sampai $900-950^{\circ} \mathrm{C}$ dalam lingkungan yang menyerahkan karbon, lalu dibiarkan beberapa waktu lamanya pada suhu tersebut dan kemudian didinginkan [1].

Setiyawan (2003), mengadakan penelitian mengenai pengaruh proses carburizing terhadap sifat fisis dan mekanis sudu blower dinamo ampere pada mobil diesel didapatkan kesimpulan bahwa lama waktu penahanan (holding time) pada material ini mempengaruhi sifat mekanis material yaitu terhadap nilai kekerasan. Dimana material dasar tanpa perlakuan memiliki kekerasan rata-rata sebesar $664,1 \mathrm{~kg} / \mathrm{mm}^{2}$, material hasil quenching $850{ }^{\circ} \mathrm{C}$ dengan holding time 1 jam sebesar 723,64 $\mathrm{kg} / \mathrm{mm}^{2}$ dan material hasil quenching $850{ }^{\circ} \mathrm{C}$ dengan holding time 2 jam sebesar 730,5 $\mathrm{kg} / \mathrm{mm}^{2}$ [2].

Fatai dkk (2010) menyelidiki proses pack carburizing pada mild steel dengan temperatur karburisasi $850^{\circ} \mathrm{C}, 900^{\circ} \mathrm{C}$ dan $950^{\circ} \mathrm{C}$, kemudian ditahan selama 15 menit dan 30 menit, lalu proses quenching dengan minyak dan tempering pada $550^{\circ} \mathrm{C}$. Hasil pengujian menunjukkan bahwa ketangguhan impact pada mild steel semakin berkurang dengan naiknya temperatur karburisasi. Sedangkan kekakuan dari mild steel semakin meningkat akibat proses karburisasi, tetapi semakin turun dengan kenaikan temperatur karburisasi. Untuk 
kekerasan permukaan pada mild steel semakin berkurang dengan naiknya temperatur [3].

Tujuan dari penelitian ini adalah untuk mengetahui pengaruh penambahan serbuk cangkang kerang mutiarapada proses pack carburizing terhadap sifat fisis (struktur mikro) dan mekanis (uji kekerasan) baja karbon rendah setelah mengalami perlakuan

\section{METODOLOGI PENELITIAN}

Alat dan bahan yang digunakan dalam penelitian ini adalah: Kotak karburisasi, tungku pemanas, Mesin polish, Mikroskop optik, Mesin uji kekerasan, Jangka sorong, Kamera, Tang penjepit, dan Amplas. Sedangkan bahan yang akan digunakan adalah baja AISI 1018, arang tongkol jagung, serbuk cangkang kerang mutiara, kertas gosok (dengan ukuran 80, 100,
400, 600, 800, dan 1000), dan Autosol. Jumlah Spesimen yang digunakan sebanyak 93 buah, yang terdiri dari 3 spesimen awal tanpa karburasi, 90 spesimen dikarburisasi pada suhu $910^{\circ} \mathrm{C}, 930^{\circ} \mathrm{C}$ dan $950^{\circ} \mathrm{C}$ dengan waktu holding selama 90 menit dan 150 menit, dengan 5 variasi media karburizer dan 3 kali pengulangan $(5 \times 3 \times 2 \times 3)$.

Kotak terbuat dari baja karbon rendah dengan ketebalan $5 \mathrm{~mm}$ dengan ukuran panjang $500 \mathrm{~mm}$, lebar $100 \mathrm{~mm}$ dan tinggi 100 $\mathrm{mm}$, disekat menjadi 5 bagian (sesuai dengan komposisi media carburizer) benda-benda uji tersebut dimasukkan kedalam kotak karburisasi disusun seperti Gambar dibawah ini dengan jarak tiap-tiap spesimen

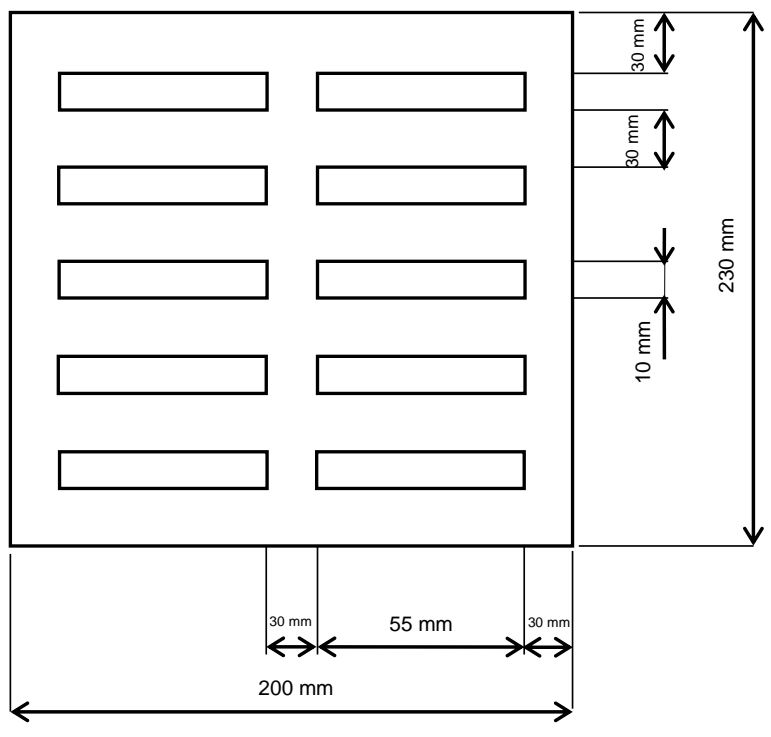

a. Tampak Atas

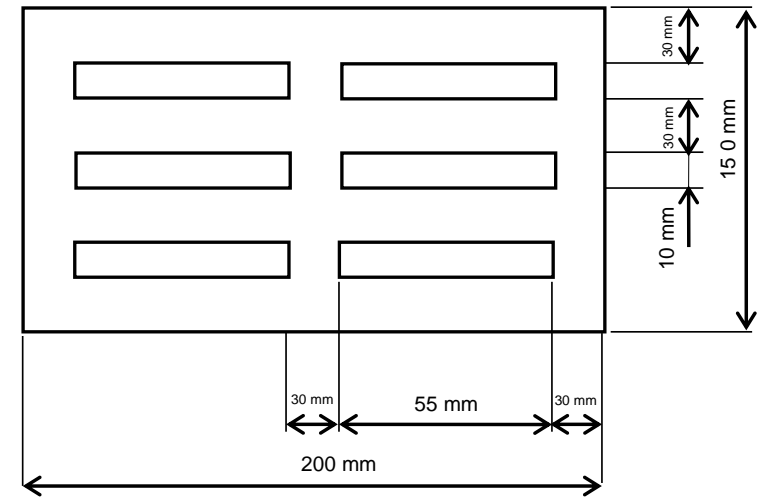

b. Tampak Depan

Gambar 1. Skema instalasi penelitian

\section{HASIL DAN PEMBAHASAN Hasil Uji Kekerasan}

Pengujian kekerasan permukaan yang dipakai adalah metode Vickers dengan beban $(\mathrm{P})$ sebesar $60 \mathrm{Kg}$. Pengujian ini dilakukan di Laboratorium Metalurgi Jurusan Teknik Mesin Fakultas Teknik Universitas Mataram. Adapun pengaruh konsentrasi serbuk cangkang Kerang mutiara dan waktu penahan terhadap nilai kekerasan dapat dilihat pada Gambar 1 sampai 3. Dari Gambar 1 sampai Gambar 3 dapat dilihat bahwa pada spesimen material awal memiliki nilai kekerasan yang sangat rendah ini dikarenakan tidak adanya penambahan karbon pada material. Spesimen dengan waktu pemanasan 150 menit pada suhu $950^{\circ} \mathrm{C}$ memiliki nilai kekerasan paling tinggi (262.27 $\mathrm{Kg} / \mathrm{mm}^{2}$ ) dibandingkan dengan proses lainnya dan matarial awal, dikarenakan adanya karbon aktif dan didukung oleh penambahan $20 \%$ serbuk cangkang kerang mutiara sebagai 
energizer sehingga karbon lebih cepat berdifusi kedalam material.

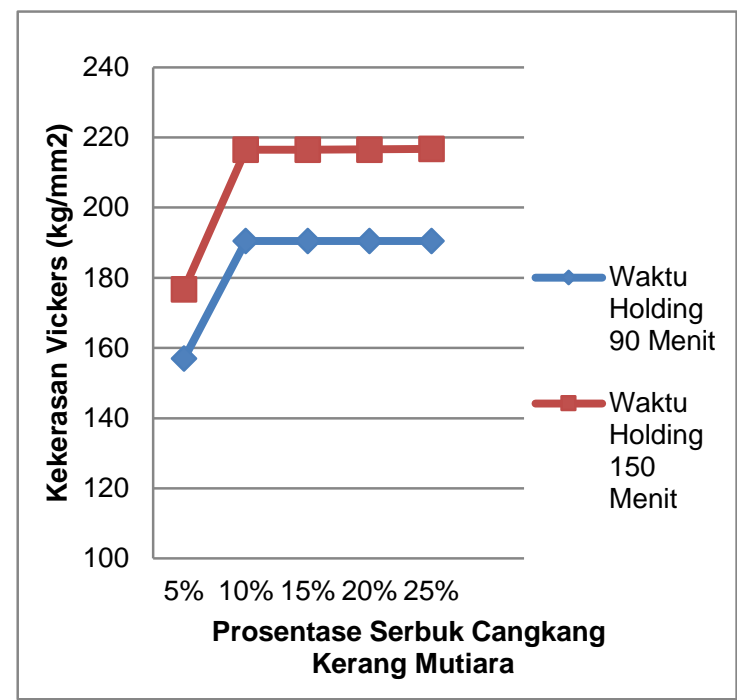

Gambar 1. Pengaruh prosentase SCKM terhadap nilai kekerasan pada suhu $910^{\circ} \mathrm{C}$

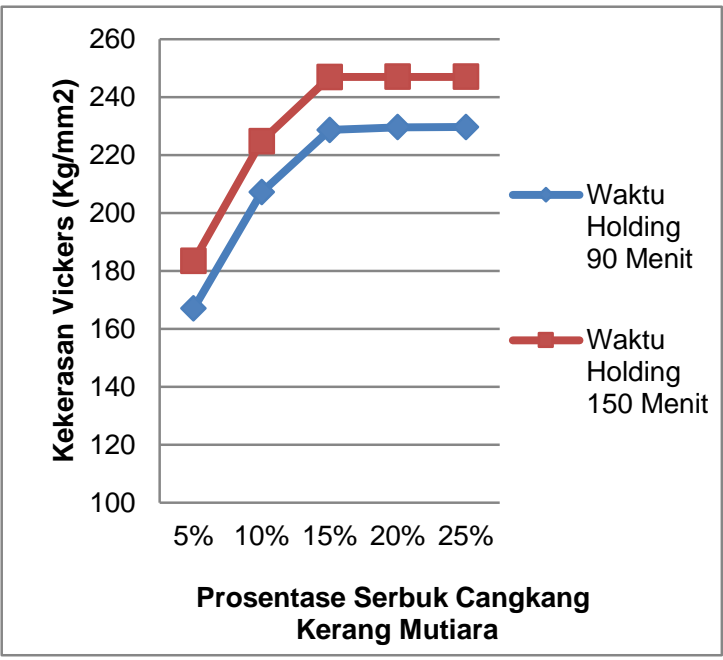

Gambar 2. Pengaruh prosentase SCKM terhadap nilai kekerasan pada suhu $930^{\circ} \mathrm{C}$

Dalam proses ini jika serbuk cangkang kerang mutiara semakin banyak di imbangi dengan suhu holding yang lama maka karbon yang berdifusi ke baja akan semakin cepat dan membuat nilai kekerasan permukaan dari baja akan semakin besar, sehingga karbon akan lebih mudah berdifusi di antara celah-celah atom Fe. Pada proses carburizing dengan penambahan $20 \%$ serbuk cangkang dengan menggunakan pada suhu pemanasan $950^{\circ} \mathrm{C}$ dan waktu holding 150 menit diperoleh harga kekerasan tertinggi sebesar $262.27 \mathrm{Kg} / \mathrm{mm}^{2}$ disusul dengan suhu pemanasan $930^{\circ} \mathrm{C}$, sebesar $247.06 \mathrm{~kg} / \mathrm{mm}^{2}$ dengan waktu penahanan 150 menit dan penambahan 20\% serbuk serbuk cangkang kerang mutiara, dan pada suhu pemanasan $910^{\circ} \mathrm{C}$ didadapatangka kekerasan $216.51 \mathrm{~kg} / \mathrm{mm}^{2}$, dan penambahan $15 \%$ serbuk cangkang kerang mutiara dengan waktu holding yang sama.

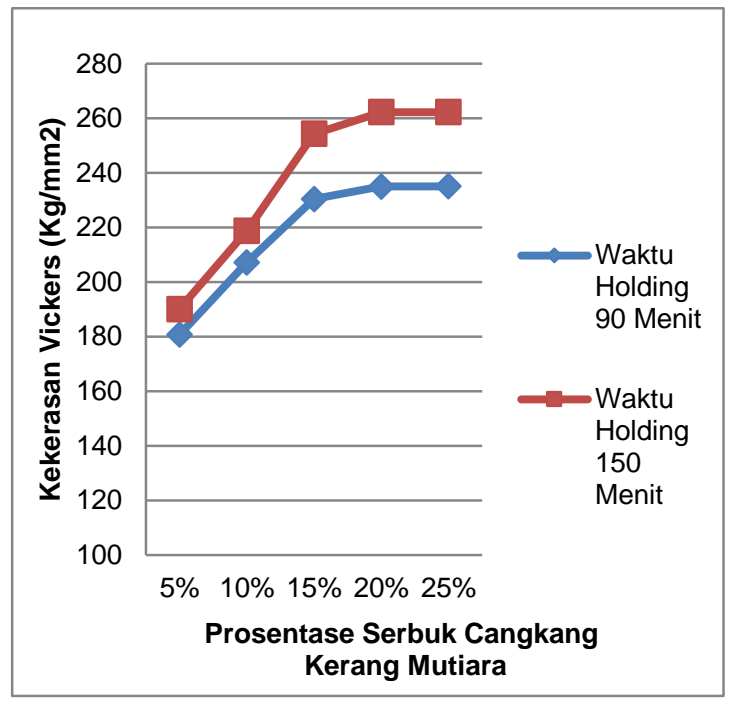

Gambar 3. Pengaruh prosentase SCKM terhadap nilai kekerasan pada suhu $950^{\circ} \mathrm{C}$

\section{Hasil Uji Struktur Mikro}

Hasil pengamatan struktur mikro dari material awal sebelum mengalami pack caburizing dapat dilihat pada Gambar 4. Gambar 4 menunjukkan bahwa ferrite (berwarna terang dan putih) dan peralite (yang berwarna gelap dan hitam) lebih besar ukurannya dibandingkan dengan karbida. Karbida akan membesar jika terjadi perlakuan panas terhadap benda kerja (baja karbon rendah). Kemudian struktur ferrite lebih dominan dari pada struktur pearlite yang lebih sedikit jumlahnya, sehingga kekerasan dari material awal menjadi lebih rendah. Hal ini terjadi karena tidak adanya penambahan unsur karbon yang diberikan pada matrial awal dan sesuai dengan kandungan karbon yang terkandung pada material awal sebesar $0.159 \% \mathrm{C}$. 


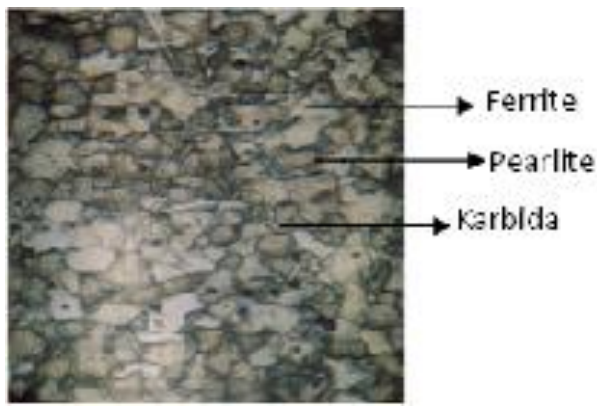

Gambar 4. Struktur Mikro material awal dengan pembesaran 400 kali

Hasil pengamatan struktur mikro dari material yang telah mengalami pack caburizing dengan perbandingan konsentrasi $85 \%$ arang kayu jati dan $15 \%$ serbuk cangkang kerang mutiara pada suhu $950^{\circ} \mathrm{C}$ dengan waktu carburizing 6 jam menggunakan media pendingin air tawar dapat dilihat pada Gambar 5 berikut ini.

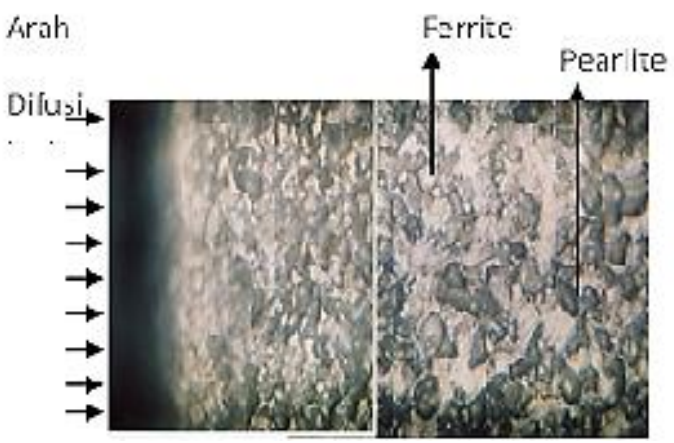

Gambar 5. Struktur mikro dengan pembesaran 400 kali.

Gambar 5 menunjukkan bahwa strukturstruktur perlit jumlahnya semakin banyak dan ukuran butirannya mulai merata di sepanjang penetrasi walaupun pada sisi perlitnya masih terdapat banyak ferit. Peningkatan jumlah pearlite yang lebih banyak dibandingkan dengan struktur mikro material awal dapat terjadi karena adanya pengaruh penambahan unsur karbon ke dalam material selama proses difusi intertisi karbon dengan cara pemanasan pada material pada temperatur $950^{\circ} \mathrm{C}$ dengan lama waktu penahan 6 jam serta adanya penambahan serbuk cangkang kerang mutiara dengan konsentrasi $15 \%$ (\%berat) sebagai energizer yang merupakan unsur untuk mempercepat proses difusi karbon ke dalam baja sehingga dapat membentuk struktur pearlit lebih banyak. Sehingga menjadikan spesimen ini menjadi lebih keras dari sebelumnya dan juga di pengaruhi oleh terjadinya proses pendinginan yang cepat sehingga dapat merubah sifat fisis dari pada baja.

Hasil pengamatan struktur mikro dari material yang telah mengalami pack caburizing dengan perbandingan konsentrasi $90 \%$ arang tongkol jagung dan $10 \%$ serbuk cangkang kerang mutiara pada suhu $950^{\circ} \mathrm{C}$ dengan waktu carburizing 150 menit dapat dilihat pada Gambar 6 berikut ini.

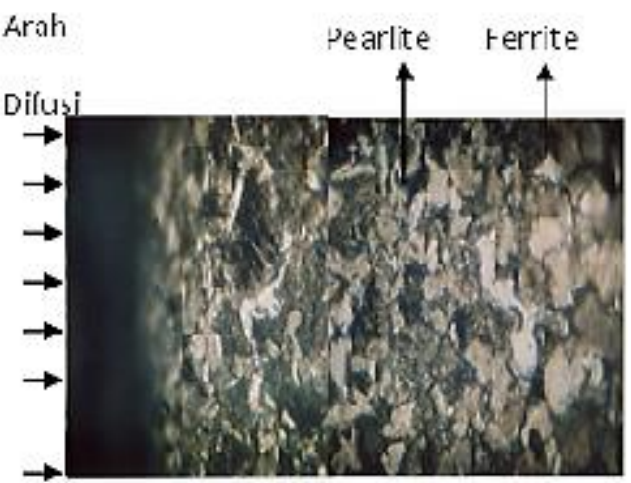

Gambar 6. Struktur mikro dengan pembesaran 400 kali.

Dari Gambar 6 menunjukkan bahwa peningkatan jumah perlit yang paling banyak dibandingkan dengan struktur mikro yang lain, selai itu penetrasi dari karbon juga cukup dalam dan butiran-butiran pada perlit ukurannya lebih besar dibandingkan dengan konsentrasi sebelumnya. Dengan ukuran butir yang lebih besar maka kekerasan yang dihasilkan juga akan lebih besar. Ini terjadi karena adanya perbandingan bahan tambahan yang berupa $90 \%$ arang tongkol jagung dan $10 \%$ serbuk cangkang kerang mutiara sebagai energizer yang merupakan bahan pembangkit tenaga dalam proses karburisasi, serta didukung dengan proses quenching menggunakan media pendingin larutan garam. Hal ini dapat meningkatkan jumlah karbon yang cukup banyak, sehinga pada saat pemanasan berlangsung difusi karbon ke dalam baja menjadi lebih cepat sehingga dapat merubah butir struktur mikro dan nilai kekerasan yang lebih keras di bandingkan dengan material uji sebelumnya 


\section{KESIMPULAN}

Dari hasil pengujian dan pembahasan dapat disimpulkan bahwa:

1. Variasi komposisi media karburizer dan penambahan serbuk cangkang kerang mutiara berpengaruh terhadapa nilai kekerasan baja karbon rendah.

2. Keefektifan penambahan serbuk kerang mutiara tergantung pada suhu pemanasan. Penambahan $20 \%$ serbuk kerang mutiara (SKM) akan berpengaruh terhadap kenaikkan angka kekerasan pada pemanasan pada suhu $950^{\circ} \mathrm{C}$. Pada suhu pemanasan $910^{\circ} \mathrm{C}$ dan $930^{\circ} \mathrm{C}$, penambahan $20 \%$ (SKM), kenaikkan nilai kekerasan pemukaan cenderung stagnan. Demikian pula untuk proesentase $15 \%$ dan $10 \%$ (SKM) Nilai kekerasan rata-rata akan mengalami stagnan pada suhu pemanasan $910^{\circ} \mathrm{C}$ dan $930^{\circ} \mathrm{C}$

3. Waktu holding berpengaruh terhadap kenaikkan angka kekerasan spesiment.

4. Angka kekerasan tertinggi sebesara $262.47 \mathrm{Kg} / \mathrm{mm}^{2}$ didapatkan pada suhu pemanasan $950^{\circ} \mathrm{C}$, waktu holding 150 dengan variasi media carburizer $80 \%$ arang tongkol jagung dan $20 \%$ SKM.

5. Dari pengamatan foto struktur mikro pada material awal terdapat struktur ferrite yang lebih banyak di bandingkan dengan foto struktur mikro setelah perlakuan (carburizing). Sebaliknya jumlah pearlite setelah perlakuan (carburizing) menjadi lebih banyak dibanding material sebelumnya.
[2] Setiyawan, A., 2003. Penelitian Mengenai Pengaruh Proses Carburizing Terhadap Sifat Fisis dan Mekanis Sudu Blower Dinamo Ampere pada Mobil Diesel, Tugas Akhir, Universitas Muhammadiyah Surakarta

[3] Fatai O. A., Simeon A. I., Isiaka., Oluwole O., and Joseph O. B., 2010. Pack Carburization of Mild Steel, using Pulverized Bone as Carburizer: Optimizing Process Parameters, Leonardo Electronic Journal of Practices and Technologies, ISSN 1583-1078, issue 16, p. 1-12

\section{DAFTAR PUSTAKA}

[1] Amanto, H. \& Daryanto, 1999. Ilmu Bahan, Bumi Aksara, Jakarta 